\title{
Comparison of the changes in adenine nucleotides of rat liver mitochondria induced by tamoxifen and 4-hydroxytamoxifen
}

\author{
Carla M.P. Cardoso ${ }^{\mathrm{a}, \mathrm{b}}$, António J.M. Moreno ${ }^{\mathrm{b}}$, Leonor M. Almeida ${ }^{\mathrm{a}, \mathrm{b}}$, \\ José B.A. Custódio ${ }^{\mathrm{a}, \mathrm{b}, *}$ \\ ${ }^{a}$ Laboratório de Bioquímica, Faculdade de Farmácia, Couraça dos Apóstolos, 51 r/c, 3000-295 Coimbra, Portugal \\ ${ }^{\mathrm{b}}$ Centro de Neurociências de Coimbra, Universidade de Coimbra, Portugal
}

Accepted 31 May 2003

\begin{abstract}
The antiestrogen tamoxifen (TAM) inhibits the growth of different estrogen receptor (ER)-negative cells. Recently, multiple effects of TAM on mitochondrial bioenergetic functions have been pointed to explain its ER-independent cell death mechanisms. We have shown that TAM and its major active metabolite 4-hydroxytamoxifen (OHTAM) induce depolarization of the mitochondrial membrane potential $(\Delta \Psi)$ and uncouple the mitochondrial respiration, depressing the oxidative phosphorylation efficiency. To clarify the biochemical mechanisms underlying the changes in the regulation of ATP synthesis and yield, in this work we evaluated the alterations of mitochondrial adenine nucleotides induced by both drugs and ascertained whether such changes could reflect a specific inhibition of either the adenine nucleotide translocase (ANT) or the phosphate carrier, as well as the activation of ATP hydrolysis due to $\Delta \Psi$ depolarization. We found that both antiestrogens caused a concentration-dependent decrease in mitochondrial ATP levels. Mitochondrial ADP and AMP were concomitantly increased with a subsequent decrease in the ATP/ADP or ATP/AMP ratios. The total concentration of adenine nucleotides also changed. Additionally, both drugs decreased the ANT content of mitochondria, inhibited the phosphate carrier and induced ATP hydrolysis. However, the effects of TAM were more drastic than those induced by OHTAM. Therefore, the depletion of ATP might result from an activation of ATP catabolism, as well as from a decrease in the mitochondrial content of ANT and partial inhibition of the phosphate carrier. Our data may explain the ERindependent effects and cytotoxicity of both drugs and, in agreement with other previous studies, suggest that OHTAM is much less toxic to mitochondria than TAM.
\end{abstract}

(C) 2003 Elsevier Ltd. All rights reserved.

Keywords: 4-Hydroxytamoxifen; Mitochondrial energetics; Mitochondrial adenine nucleotides; Phosphate carrier; Adenine nucleotide translocase; Tamoxifen

\section{Introduction}

The antiestrogen tamoxifen (TAM) is widely used in the treatment of breast cancer and has been recognized as a cancer chemopreventive agent in high-risk women (Neven and Vernaeve, 2000; Radmacher and Simon,

Abbreviations: BSA, bovine serum albumin; CATR, carboxyatractiloside; $\beta$-aminoethyl ether, ethylene glycol-bis; EGTA, ethylene glicol-bis ( $\beta$-aminoethyl ether) $N N N^{\prime} N$-tetraacetic acid; ER, estrogen receptor; FCCP, carbonyl cyanide $p$-trifluormethoxyphenylhydrazone; $\Delta \Psi$, mitochondrial membrane potential; HEPES, 4-(2-hydroxymethyl)-1-piperazineethanesulfonic acid; OHTAM; 4-Hydroxytamoxifen; Pi, inorganic phosphate; TAM, tamoxifen

* Corresponding author. Tel.: + 351-239-852564; fax: +351-239852569.

E-mail address: custodio@ci.uc.pt (J.B.A. Custódio).
2000). It is extensively metabolized in humans being 4-hydroxytamoxifen (OHTAM) its major active metabolite, which has been found in high levels in both the plasma and the tumor tissues (Daniel et al., 1984; Lien et al., 1991). This metabolite has been reported to possess several hundred times more affinity toward estrogen receptor (ER) as compared with TAM (Borgna and Rochefort, 1981). Thus, OHTAM is accepted as a more active drug than its precursor in retarding the estrogendependent cell growth and proliferation of ER-positive mammary tumours (Jordan et al., 1988; Osborne et al., 1992). However, large clinical trials have indicated that a favourable response to adjuvant therapy with TAM is also observed in different cell types that lack the ER (Couldwell et al., 1993; Croxtall et al., 1994; Charlier et al., 1995), thereby suggesting that, at least in part, its 
antineoplastic action may not be related to the antihormone properties of these drugs. Also, there are clinically significant ER-independent TAM actions for which the biochemical mechanisms still remain obscure.

Mitochondria, which dominate the intracellular scenery of most animal cells as their total number per cell usually far exceeds that of any organelle, are the site of most ATP cell production (Pederson, 1999), that is essential to maintain and regulate several physiological functions (Gupta et al., 2001 and references therein). Therefore, the amount of ATP available for the cell can in turn be considered as one of the key events in preserving cell integrity. Thus, chemicals causing mitochondrial damage and inducing depletion of ATP may in turn cause cell dysfunction or even cell death.

Recently we have shown that TAM depresses the oxidative phosphorylation efficiency and uncouples the mitochondrial respiration (Cardoso et al., 2001) and that OHTAM affects the phosphorylation capacity of mitochondria in a slight way as compared with the damaging effects of TAM (Cardoso et al., 2002). These effects are essentially a consequence of the membrane potential $(\Delta \Psi)$ depolarization due to an increase in the proton leak through the mitochondrial inner membrane (Cardoso et al., 2002). Therefore, the cytotoxicity of these drugs is associated with ATP depletion via impairment of mitochondria function related to $\Delta \Psi$ and/or oxidative phosphorylation. However, although the ATPsynthase couples the transport of the protons across the membrane to the synthesis of ATP inside the mitochondrial matrix, the phosphate for the phosphorylation is imported into the mitochondria by the phosphate carrier and the ATP is exported to the cytosol in exchange for ADP by the adenine nucleotide translocase (ANT).

Since the TAM action on mitochondrial phosphorylation is not completely understood and its OHTAM metabolite has been shown to possess growth inhibitory activity, the aim of this work was mainly to evaluate the alterations of mitochondrial energetic charge induced by both drugs and ascertain whether such changes could reflect a specific inhibition of either the ANT or the phosphate carrier, as well as the activation of ATP hydrolysis.

\section{Materials and methods}

\subsection{Chemicals}

Bovine serum albumin (BSA), 4-(2-hydroxymethyl)-1piperazineethanesulfonic acid (HEPES), ethylene glycol-bis ( $\beta$-aminoethyl ether) $N N N^{\prime} N^{\prime}$-tetraacetic acid (EGTA), 5, 5'-dithio-bis(2-nitrobenzoic acid), $N$-ethylmaleimide, oligomycin, 4-Hydroxytamoxifen (OHTAM), tamoxifen (TAM) and ATP, ADP and AMP for HPLC analysis were obtained from Sigma Chemical Co (St. Louis, MO). Carbonyl cyanide $p$-trifluormethoxyphenylhydrazone (FCCP) and sucrose were obtained from Merck (Dramstadt, Germany). All other chemicals were commercial products of the highest purity grade available and solutions were prepared in deionized ultra pure water.

\subsection{Preparation of rat liver mitochondria}

Mitochondria were isolated from the liver of overnight fasted Wistar rats $(250-300 \mathrm{~g})$ of either sex by differential centrifugation as described elsewhere (Cardoso et al., 2001), with slight modifications. Animals were killed by cervical dislocation and the liver was quickly homogenized. The homogenate was prepared in $250 \mathrm{mM}$ sucrose, $10 \mathrm{mM}$ HEPES (pH 7.4), $1 \mathrm{mM}$ EGTA and $0.1 \%(\mathrm{w} / \mathrm{v})$ free fatty acid BSA. The liver homogenate was centrifuged at $500 \mathrm{~g}$ for $10 \mathrm{~min}$ at $4{ }^{\circ} \mathrm{C}$ and mitochondria were recovered from the supernatant by centrifugation at $10000 \mathrm{~g}$ for $10 \mathrm{~min}$. The mitochondrial pellet was resuspended twice in the washing medium containing $250 \mathrm{mM}$ sucrose, $10 \mathrm{mM}$ HEPES, $\mathrm{pH}$ 7.2. Mitochondrial protein was determined by the biuret method using BSA as the standard (Gornall et al., 1949).

\subsection{Mitochondrial respiration}

The oxygen consumption of isolated mitochondria was measured polarographically using a Clark-type oxygen electrode (YSI model 5331, Yellow Spring Inst.), in a $1 \mathrm{ml}$ thermostated water-jacketed closed chamber with magnetic stirring and connected to a suitable recorder. OHTAM and TAM in ethanolic solutions (up to $6 \mu \mathrm{l}$ ) were incubated for $3 \mathrm{~min}$ at $25^{\circ} \mathrm{C}$ in $1 \mathrm{ml}$ of the standard respiratory medium consisting of $130 \mathrm{mM}$ sucrose, $50 \mathrm{mM} \mathrm{KCl}, 2.5 \mathrm{mM} \mathrm{MgCl} 2,2.5 \mathrm{mM} \mathrm{KH}_{2} \mathrm{PO}_{4}$, $5 \mathrm{mM}$ HEPES, $0.1 \mathrm{mM}$ EGTA, pH 7.2, previously supplemented with mitochondria $(1 \mathrm{mg})$ and $4 \mu \mathrm{M}$ rotenone. State 4 respiration was initiated with $5 \mathrm{mM}$ succinate and ADP (150 nmol/mg protein) was added to establish state 3 respiration. Respiration rates were calculated assuming an oxygen concentration of $240 \mathrm{nmol}$ $\mathrm{O}_{2} / \mathrm{ml}$ in the experimental medium at $25^{\circ} \mathrm{C}$.

For the titration experiments with carboxyatractiloside (CATR) the respiration of isolated mitochondria $(0.5 \mathrm{mg} / \mathrm{ml})$ was determined at $25^{\circ} \mathrm{C}$ using also a Clark oxygen electrode. The respiratory medium contained $200 \mathrm{mM}$ sucrose, $5 \mathrm{mM}$ succinate (sodium salt), $5 \mu \mathrm{M}$

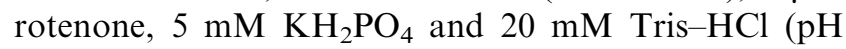
7.4). The ANT content was determined by titrating the rate of state 3 respiration with increasing concentrations of CATR (Vignais, 1976). Mitochondria were pre-incubated with CATR in the respiratory medium for $1 \mathrm{~min}$ before ADP $(0.1 \mathrm{mM})$ addition to initiate state 3 
respiration. Plots of $\mathrm{O}_{2}$ consumption versus CATR appeared biphasic, with an increasing inhibitory segment followed by a steady respiration indicating that state 3 respiration was completely inhibited. The mitochondrial content of ANT was determined by the amount of CATR required to completely inhibit state 3 respiration, assuming a 1:1 binding stoichiometry, which was expressed as CATR content per mg mitochondrial protein (Roussel et al., 2000; Zhou et al., 2001).

\subsection{Enzymatic activities}

ATP-synthase activity was determined by measuring the $\mathrm{pH}$ changes of the medium associated with ATP synthesis as reported by Moreno and Madeira (1991). The reactions were carried out at $25^{\circ} \mathrm{C}$ in $2 \mathrm{ml}$ of reaction medium containing $130 \mathrm{mM}$ sucrose, $50 \mathrm{mM} \mathrm{KCl}$, $2.5 \mathrm{mM} \mathrm{MgCl}_{2}, 5 \mathrm{mM} \mathrm{KH}_{2} \mathrm{PO}_{4}, 0.5 \mathrm{mM}$ HEPES, 0.1 mM EGTA, pH 7.2, supplemented with $2 \mu \mathrm{M}$ rotenone, $150 \mu \mathrm{M}$ ADP and mitochondria $(1 \mathrm{mg})$. The experiments were initiated by the addition of $5 \mathrm{mM}$ succinate and TAM and OHTAM were added to induce hydrolysis of the ATP produced following ADP phosphorylation by the mitochondria. ATPase activity was estimated by monitoring the $\mathrm{pH}$ changes of the same medium associated with ATP hydrolysis (Madeira et al., 1974).

\subsection{HPLC determination of adenylates}

Adenine nucleotides (ATP, ADP and AMP) were extracted using an acidic extraction procedure and separated by reverse-phase HPLC as described by Stochi et al. (1985). Briefly, the acidic extraction was performed as follows: $1 \mathrm{mg}$ mitochondria protein was incubated in $1 \mathrm{ml}$ standard respiratory medium containing $130 \mathrm{mM}$ sucrose, $50 \mathrm{mM} \mathrm{KCl}, 2.5 \mathrm{mM} \mathrm{MgCl}_{2}$, $2.5 \mathrm{mM} \mathrm{KH}_{2} \mathrm{PO}_{4}, 5 \mathrm{mM}$ HEPES, $0.1 \mathrm{mM}$ EGTA, pH 7.2 , supplemented with $4 \mu \mathrm{M}$ rotenone. TAM or OHTAM were added at the concentrations of 20,40 and $60 \mathrm{nmol} / \mathrm{mg}$ protein. A control assay in the absence of any of those drugs, was also carried out. After the incubation period $(3 \mathrm{~min}), 5 \mathrm{mM}$ succinate was added to induce state 4 respiration and, 2 min later, $150 \mathrm{nmol}$ ADP were added to the reaction vessel to induce state 3 respiration. After $1 \mathrm{~min}$ of reaction, $250 \mu \mathrm{l}$ of the suspension were added to $250 \mu \mathrm{l}$ ice-cooled $\mathrm{HClO}_{4} 0.6 \mathrm{M}$ (EDTA-Na $25 \mathrm{mM}$ ). After vortexing, this mixture was centrifuged at $10000 \mathrm{rpm}$ for $2 \mathrm{~min}$ at $4{ }^{\circ} \mathrm{C}$ in an Eppendorf table centrifuge (UNIEQUIP UEC 14/B) and the pellet was discarded. The supernatant was neutralized with $\mathrm{KOH} 3 \mathrm{M}$ (Tris $1.5 \mathrm{M}$ ) and centrifuged again $(10000 \mathrm{rpm}, 2 \mathrm{~min})$ to precipitate all the $\mathrm{KClO}_{4}$ produced. The supernatant was then stored at $-80{ }^{\circ} \mathrm{C}$ for further chromatographic analysis. All the extraction procedure was carried out at $0-4{ }^{\circ} \mathrm{C}$ to minimize degradation of nucleotides. The chromatographic apparatus was a Beckman System Gold, consisting of a binary pump (model 126) and a variable UV detector (model 166), controlled by a computer. The detection wavelength was $254 \mathrm{~nm}$ and the column was a Lichrospher 100 RP-18 $(5 \mu \mathrm{M})$ from Merck (Darmstadt, Germany). An isocratic elution with $100 \mathrm{mmol} / 1$ phosphate buffer $\left(\mathrm{KH}_{2} \mathrm{PO}_{4}\right)(\mathrm{pH} 6.5)$ and $1.2 \%$ methanol was performed with a flow rate of $1 \mathrm{ml} / \mathrm{min}$. The time required for each analysis was about $5 \mathrm{~min}$.

\subsection{Mitochondrial swelling}

Mitochondrial osmotic volume changes were measured by the apparent absorbance changes at $540 \mathrm{~nm}$, with a Perkin-Elmer Lambda $6 \mathrm{UV} / \mathrm{vis}$ spectrophotometer computer controlled (Norwalk, USA). The reactions were carried out at $25{ }^{\circ} \mathrm{C}$ in $2.5 \mathrm{ml}$ of the required isoosmotic media: $135 \mathrm{mM}$ ammonium phosphate, $5 \mathrm{mM}$ HEPES, $0.1 \mathrm{mM}$ EDTA, $2 \mu \mathrm{M}$ rotenone (pH 7.2).

\section{Results}

To assess whether TAM or OHTAM affect the mitochondrial bioenergetic charge, we determined the ATP, ADP and AMP levels in rat liver mitochondria under the action of different concentrations of both drugs. As shown in Table 1, the pre-incubation of mitochondria with TAM or OHTAM for $3 \mathrm{~min}$, before energization with succinate, causes a concentration-dependent decrease in ATP levels, with concomitant increases in levels of ADP and AMP in the mitochondrial population. The total concentration of adenine nucleotides also changes. Moreover, both drugs decrease the ATP/ADP and ATP/AMP concentration ratios as a consequence of

Table 1

Changes in the concentrations of adenine nucleotides in rat liver mitochondria induced by different concentrations of TAM and OHTAM $^{a}$

\begin{tabular}{lrcr}
\hline & \multicolumn{1}{c}{ ATP } & \multicolumn{1}{c}{ ATP/ADP } & \multicolumn{1}{c}{ ATP/AMP } \\
\hline Control & $189.90 \pm 7.07$ & $203.62 \pm 97.77$ & $9.88 \pm 0.042$ \\
TAM 20 & $139.19 \pm 1.83$ & $11.26 \pm 0.078$ & $6.96 \pm 0.042$ \\
TAM 40 & $81.95 \pm 3.07$ & $2.46 \pm 0.014$ & $2.80 \pm 0.007$ \\
TAM 60 & $25.97 \pm 5.59$ & $0.515 \pm 0.021$ & $0.275 \pm 0.021$ \\
OHTAM 20 & $166.72 \pm 3.82$ & $12.75 \pm 0.17$ & $5.70 \pm 0.078$ \\
OHTAM 40 & $118.77 \pm 4.18$ & $6.72 \pm 0.007$ & $5.73 \pm 0.050$ \\
OHTAM 60 & $73.92 \pm 1.55$ & $2.28 \pm 0.009$ & $1.20 \pm 0.007$ \\
\hline
\end{tabular}

a Mitochondria $(1 \mathrm{mg})$ in $1 \mathrm{ml}$ of the standard respiratory medium were previously incubated with different concentrations of TAM or OHTAM (20, 40 and $60 \mathrm{nmol} / \mathrm{mg}$ protein) for $3 \mathrm{~min}$ and adenine nucleotides concentrations were determined by HPLC, as described in Section 2. Each value ( $\mathrm{nmol} / \mathrm{mg}$ protein) represents the mean \pm S.D. of at least three independent determinations. 
ATP levels depletion and increases in ADP and AMP levels. These effects are more pronounced with TAM as compared to OHTAM, according to other observed effects on mitochondrial bioenergetic functions (Cardoso et al., 2001, 2002).

Our recent reports pointing to a decrease in the oxidative phosphorylation capacity of mitochondria treated with either TAM or OHTAM, as a consequence of proton leak across the mitochondrial inner membrane (Cardoso et al., 2001, 2002), led us also to investigate whether the ANT and/or the phosphate carrier are
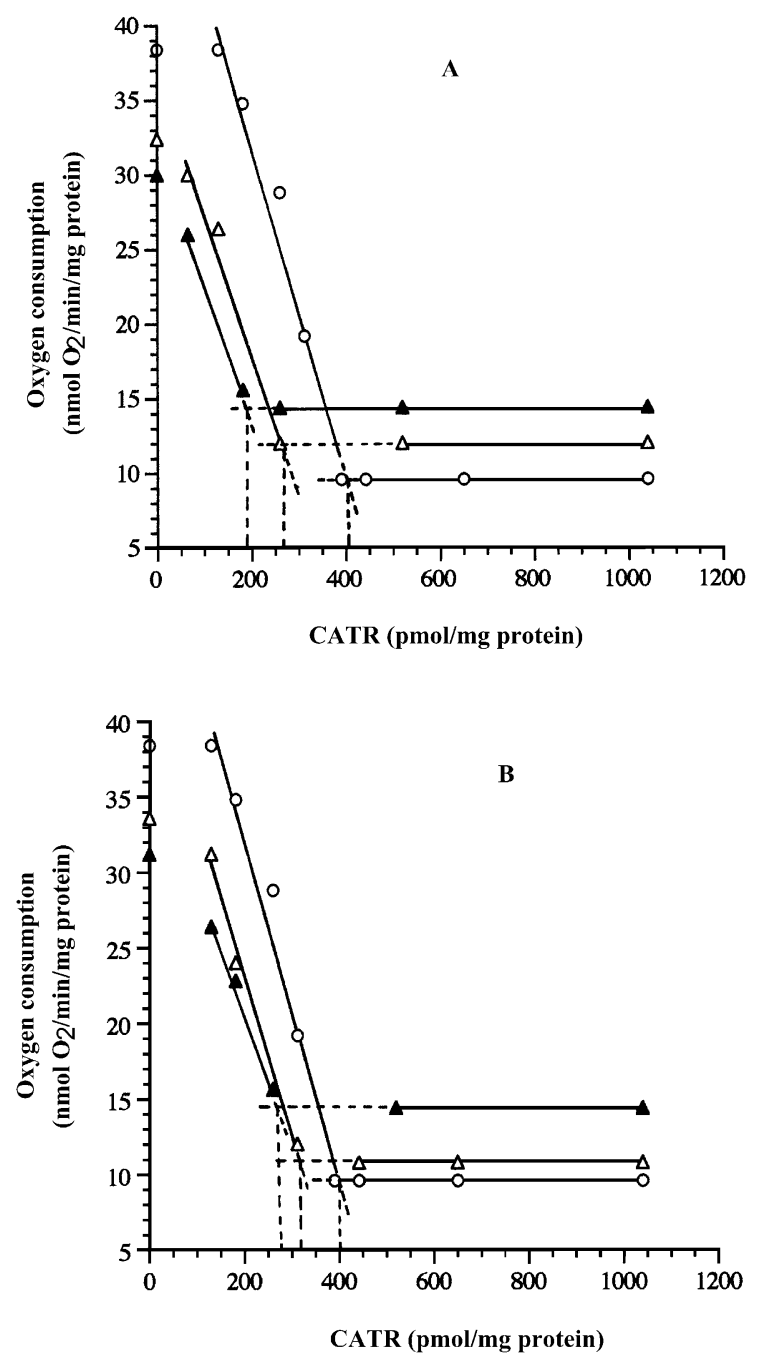

Fig. 1. Determination of mitochondrial ANT content by titration of active respiration with carboxyatractiloside (CATR). Mitochondria $(0.5 \mathrm{mg})$ in $1 \mathrm{ml}$ of the respiratory medium containing $200 \mathrm{mM}$ sucrose, $5 \mathrm{mM}$ succinate, $5 \mu \mathrm{M}$ rotenone, $5 \mathrm{mM} \mathrm{KH}_{2} \mathrm{PO}_{4}$ and $20 \mathrm{mM}$ Tris- $\mathrm{HCl}$ ( $\mathrm{pH}$ 7.4) were pre-incubated with different concentrations of CATR during $2 \mathrm{~min}$, after a previous incubation for $3 \mathrm{~min}$, in the absence $(\bigcirc)$ or presence of $20(\triangle)$ and $40(\boldsymbol{\Delta}) \mathrm{nmol} \mathrm{TAM} / \mathrm{mg}$ protein (A) or $20(\triangle)$ and $40(\Delta)$ nmol OHTAM/mg protein (B). The reaction was started by the addition of $0.1 \mathrm{mM}$ ADP to initiate state 3 respiration and mitochondrial respiration rates were determined by $\mathrm{O}_{2}$ consumption with a Clark-type electrode. A representative pattern of titration curves shows the method of estimation of ANT content. involved in changes of oxidative phosphorylation efficiency induced by both drugs. Thus, to assess the involvement of ANT, titrations with CATR, an inhibitor of the mitochondrial ANT, were performed. Rat liver mitochondria were pre-incubated with TAM or OHTAM (20 and $40 \mathrm{nmol} / \mathrm{mg}$ protein) and the results are shown in Figs. 1 and 2. In both cases, either with TAM (Fig. 1A) or with OHTAM (Fig. 1B), the ANT sites were blocked by lower concentrations of CATR than in the control assay without drugs, suggesting that both drugs could affect the phosphorylation efficiency by interference with the ANT.

CATR reacts with the ANT in a 1:1 stoichiometry (Vignais, 1976; Klingenberg et al., 1975; Zhou et al., 2001). Accordingly, the ANT content in mitochondria can be estimated by titrating the active-state respiration with CATR as illustrated in Fig. 1. The mitochondrial content of active ANT was determined by the amount
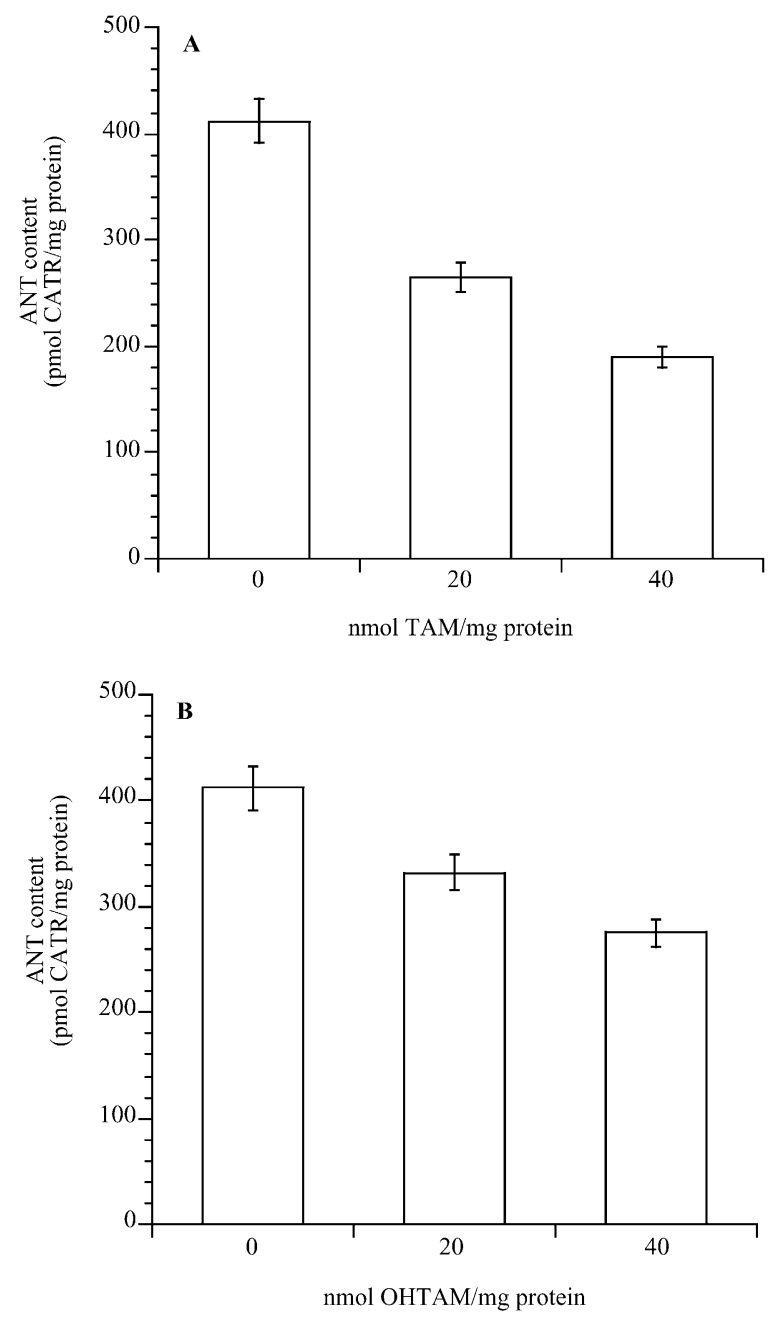

Fig. 2. ANT contents of mitochondria treated with TAM (A) or OHTAM (B). The individual ANT contents were determined from the types of experiments as shown in Fig. 1 and are expressed as pmol CATR $/ \mathrm{mg}$ mitochondrial protein. The values represent the means \pm S.D. of three mitochondrial preparations. 
of CATR required to reduce state 3 respiration to the state 4 respiratory rate, when CATR presumably saturates the translocase sites (Vignais, 1976), and the results are shown in Fig. 2A and B. TAM decreases the ANT content of mitochondria in a higher extension than OHTAM in relation to the control (Fig. 2), i.e., mitochondria incubated without the drugs. In fact, OHTAM and TAM at concentrations of $20 \mathrm{nmol} / \mathrm{mg}$ protein induce decrease in the ANT content to about 81 and $64 \%$ of the control, respectively. Moreover, while mitochondria pre-incubated with $40 \mathrm{nmol}$ OHTAM/mg protein still exhibit $67 \%$ of the ANT content, they only exhibit $46 \%$ of this at the same concentration of TAM. Such decrease in ANT content correlates with both the decrease in phosphorylation efficiency of mitochondria (Cardoso et al., 2002) and the changes in the ATP levels induced by both drugs (Table 1). Therefore, the mechanisms underlying the induced ATP depletion can in theory be caused either by inhibition of ATP synthesis due to $\Delta \Psi$ depolarization or by changes in mitochondrial ANT content. However, either the putative inhibition of the phosphate carrier or the degradation of ATP to ADP and AMP can not be excluded.

In order to investigate the effect of both antiestrogens on mitochondrial phosphate transport, the permeability of the inner mitochondrial membrane in isoosmotic medium of ammonium phosphate was analysed by monitoring the mitochondrial swelling at $540 \mathrm{~nm}$ (Fig. 3). After suspension in isoosmotic ammonium phosphate, mitochondria swell spontaneously since,

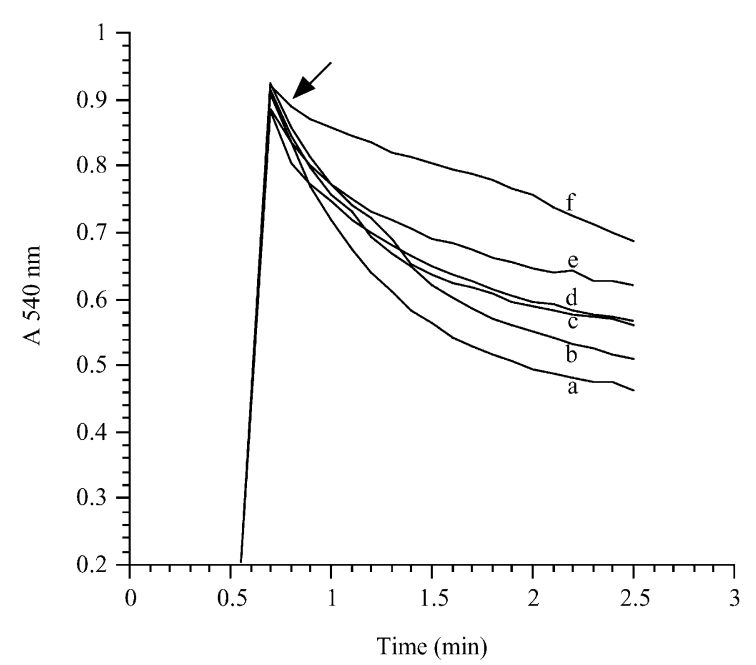

Fig. 3. Effects of TAM and OHTAM on swelling of mitochondria, followed by monitoring the decrease in absorbance at $540 \mathrm{~nm}$. Mitochondria $(0.5 \mathrm{mg})$ were suspended in $2.5 \mathrm{ml}$ of isoosmotic ammonium phosphate medium containing $5 \mathrm{mM}$ HEPES, $0.1 \mathrm{mM}$ EDTA, 135 $\mathrm{mM}$ ammonium phosphate, $2 \mu \mathrm{M}$ rotenone, $\mathrm{pH}$ 7.2. The reactions were started at $25^{\circ} \mathrm{C}$ by the addition of mitochondria in the absence (a) and presence of 20 (b) and $40 \mathrm{nmol}$ (c) OHTAM/mg protein or 20 (d) and 40 (e) nmol TAM $/ \mathrm{mg}$ protein or $2 \mu \mathrm{mol} N$-ethylmaleimide $/ \mathrm{mg}$ protein (f), added as indicated by the arrow. The traces are typical of four experiments with different mitochondrial preparations. accompanying Pi accumulation, driven by its concentration gradient, there is one proton entry, as dictated by transport through the Pi carrier and matrix acidification takes place causing accumulation of matrix $\mathrm{NH}_{4}^{+}$after diffusion of $\mathrm{NH}_{3}$ across the inner membrane (Klingenberg, 1970; Klingenberg et al., 1974) (Fig. 3line a). Therefore, after $\mathrm{NH}_{3}$ permeation through the mitochondrial membrane, the resulting ammonium phosphate entry leads to the influx of water molecules with the consequent mitochondrial swelling. In agreement with this interpretation, any compound that affects the phosphate carrier induces changes in the rate of swelling of mitochondria in ammonium phosphate medium. In fact, in the presence of $N$-ethylmaleimide (Fig. 3-line f), an inhibitor of the phosphate carrier, the mitochondrial swelling in isoosmotic medium of ammonium phosphate is significantly decreased. In the presence of TAM (Fig. 3-lines d, e) and OHTAM (Fig. 3-lines b, c) a decrease occurs in mitochondrial swelling, in a concentration-dependent way, suggesting that both drugs cause a partial inhibition of the phosphate transport. This effect is higher for TAM according to its stronger inhibitory effect in phosphorylation efficiency, as compared with OHTAM (Cardoso et al., 2001, 2002). Thus, we can infer that the depression of ATP synthesis is partially related to the observed inhibition of mitochondrial phosphate transport. Therefore, we can conclude that the interference of TAM and OHTAM with oxidative phosphorylation results not only from the interference with ANT (Figs. 1 and 2) but

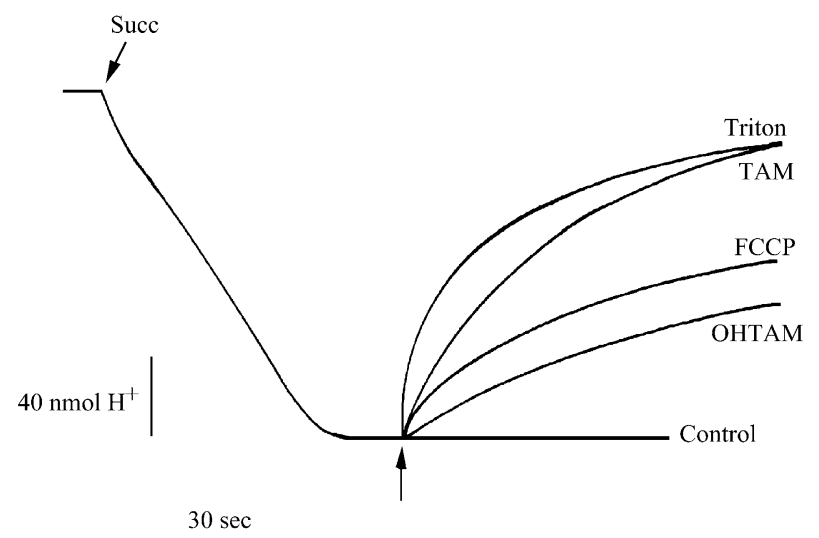

Fig. 4. Comparison of OHTAM and TAM effects on ATPase activity of intact mitochondria. The experiments were carried out at $25^{\circ} \mathrm{C}$ in 2 $\mathrm{ml}$ of reaction medium containing $130 \mathrm{mM}$ sucrose, $50 \mathrm{mM} \mathrm{KCl}, 2.5$ $\mathrm{mM} \mathrm{MgCl} 2,5 \mathrm{mM} \mathrm{KH_{2 }} \mathrm{PO}_{4}, 0.5 \mathrm{mM}$ HEPES, $0.1 \mathrm{mM}$ EGTA (pH 7.2), supplemented with $2 \mu \mathrm{M}$ rotenone, $150 \mu \mathrm{M}$ ADP and mitochondria protein $(1 \mathrm{mg})$. The reactions were started by the addition of 5 $\mathrm{mM}$ succinate and were monitored by following the production of protons with a $\mathrm{pH}$ electrode. After phosphorylation of the added ADP, TAM ( $80 \mathrm{nmol} / \mathrm{mg}$ protein), OHTAM $(80 \mathrm{nmol} / \mathrm{mg}$ protein), FCCP (4 $\mathrm{nmol} / \mathrm{mg}$ protein) and Triton X-100 $(0.1 \%)$ were added as indicated by the arrow. The traces are typical of three different experiments. 
also from the partial inhibition of phosphate transport into the mitochondria (Fig. 3).

In order to verify whether the effect of TAM and OHTAM on mitochondrial ATP levels may also result from an increase in ATP catabolism to ADP and AMP, TAM and OHTAM were added to succinate-energized mitochondria after ADP phosphorylation and the $\mathrm{H}^{+}$ consumption and production were followed by using a pH electrode (Fig. 4). In fact, ADP phosphorylation by mitochondria after addition of succinate is accomplished by $\mathrm{H}^{+}$removal from the medium associated with ATP synthesis (Fig. 4). The addition of TAM (80 $\mathrm{nmol} / \mathrm{mg}$ protein) and OHTAM $(80 \mathrm{nmol} / \mathrm{mg}$ protein), as indicated by the arrows (Fig. 4), stimulate ATP hydrolysis as proved by the release of $\mathrm{H}^{+}$to the medium, suggesting that both drugs increase the ATPase activity of tightly coupled intact mitochondria. However, this effect induced by OHTAM is much smaller than those promoted by FCCP $(4 \mathrm{nmol} / \mathrm{mg}$ protein $)$ and TAM, which, like Triton $(0.1 \%)$, induces disruption of the mitochondrial inner membrane integrity (Cardoso et al., 2001, 2002).

\section{Discussion}

The cytotoxic effects of TAM in estrogen-dependent breast cancer cells are mediated by high affinity binding to the ER (Coezy et al., 1982). Previous studies have reported that, in comparison with TAM, OHTAM has higher affinity and specificity for the ER (Borgna and Rochefort, 1981) and, besides being 100-200 times more potent (Osborne et al., 1992; Jordan et al., 1988), it is pharmacologically well tolerated (Sauvez et al., 1999). Although most studies of TAM have centred on its ability to compete with estrogens for binding to the ER and thereby antagonize their ability to induce conformational change in the ER and therefore activate transcription, several recent studies have described additional ER-independent activities of TAM (Perry et al., 1995; Fattman et al., 1998). In fact, TAM inhibits also the growth of other cell types including ER-negative breast cancer cells (Jordan, 1990), lung adenocarcinoma (Croxtall et al., 1994), prostate cancer (Bergan et al., 1999), ovarian carcinoma (Trope et al., 2000), virus (Laurence et al., 1990) and bacteria (Luxo et al., 1996). Furthermore, in spite of several often-conflicting studies showing that TAM and OHTAM can actively induce programmed cell death in cancer cells (Dietze et al., 2001; Mandlekar and Kong, 2001), it was reported that both drugs could induce ER-dependent and -independent programmed cell death (Obrero et al., 2002). However, the ER-independent action mechanisms of both drugs and their side effects have yet to be clarified.

Mitochondria of living cells participate in a number of different processes, among which is ATP synthesis by the oxidative phosphorylation system required to maintain the cell viability (Wallace and Starkov, 2000). ATP synthesis occurs in the inner mitochondrial membrane and requires the electron transport chain to generate the electrochemical proton gradient $(\Delta \mathrm{p})$ consisting of a membrane potential $(\Delta \Psi)$ and a $\mathrm{pH}$ gradient $(\Delta \mathrm{pH})$ (Brown, 1992). Moreover, this complex process also requires two key transport systems for the entry of ADP and inorganic phosphate into the matrix space and the ATPsynthase complex. On the other hand, almost all intracellular ATP is generated in the mitochondria and about one-third of the cellular adenine nucleotides are located in these organelles (Pederson, 1999).

Recently, we have observed that TAM and, although in a lesser extension, OHTAM induce both $\Delta \Psi$ depolarization, due to an increase in proton leak across the inner mitochondrial membrane, and uncoupling the mitochondrial respiratory chain, depressing the mitochondrial phosphorylative efficiency, as inferred from the changes in the phosphorylative cycle induced by ADP (Cardoso et al., 2002). However, it is noteworthy that the oxidative phosphorylation is seriously compromised at concentrations of TAM below those affecting the electron transfer along the respiratory chain. Therefore, in addition to the effects on redox chain and $\Delta \Psi$ depolarization, these antiestrogens could affect the rate of ATP synthesis as a consequence of ATP hydrolysis stimulation and changes in either ANT or phosphate carrier that use the components of $\Delta \mathrm{p}$.

HPLC analysis of adenine nucleotides revealed that indeed both antiestrogens decrease ATP levels, as well as ATP/ADP and ATP/AMP concentration ratios and increase ADP and AMP levels in the mitochondrial population (Table 1). However, the effects induced by TAM are more pronounced than those of OHTAM, in agreement with our previous results (Cardoso et al., 2002). In addition to the substantial alterations of mitochondrial energetic charge promoted by these drugs, the increase in the catabolism of ATP to ADP and AMP (Fig. 4) may be a key factor involved in the bioenergetic changes, rendering the mitochondria unable to fulfil the cell energy requirements. Thus, these effects reinforce that the hydrolysis of ATP (Fig. 4), in addition to the $\Delta \Psi$ depolarization as consequence of permeability to protons due to destructive effects in the structural integrity of the mitochondrial inner membrane (Cardoso et al., 2001, 2002), may also account for the decrease in ATP levels induced by both drugs. However, this decrease can also result from the partial inhibition of both the ADP-ATP carrier (Figs. 1 and 2) and the phosphate transport into the mitochondria (Fig. 3). So, our data suggest that TAM and OHTAM, in addition to the respiratory chain inhibition and membrane proton leak with consequent depolarization of $\Delta \Psi$ (Cardoso et al., 2002) disturb the mitochondrial energetic charge (Table 1), affect the mitochondrial 
transport of ADP (Figs. 1 and 2) and of Pi (Fig. 3), and stimulate the ATPase activity (Fig. 4). Taken together, these effects should be responsible for the observed decreased efficiency in the phosphorylative capacity of mitochondria induced by these drugs. It is noteworthy that in agreement with other previous studies, OHTAM is much less toxic to mitochondria than TAM.

In conclusion, the reduction in ATP levels induced by these drugs can dictate the future of the cell and the decision of the cell to undergo apoptosis and/or necrosis. Although these effects may not be specific for cancer cells, they may account for the antiproliferative ERindependent action mechanisms and for the cytotoxic effects of these drugs in different cell types.

\section{Acknowledgements}

This work was supported by POCTI 36075/FCB/2000 research program and Carla M.P. Cardoso is a recipient of a fellowship Praxis BD XXI/21600/99.

\section{References}

Bergan, R.C., Reed, E., Myers, C.E., Headlee, D., Brawley, O., Cho, H.K., Figg, W.D., Tompkins, A., Linehan, W.M., Kohler, D., Steinberg, S.M., Blagosklonny, M.V., 1999. A phase II study of high-dose tamoxifen in patients with hormone-refractory prostate cancer. Clinical Cancer Research 5, 2366-2373.

Borgna, J.-L., Rochefort, H., 1981. Hydroxylated metabolites of tamoxifen are formed in vivo and bound to estrogen receptor in target tissues. The Journal of Biological Chemistry 256, 859-868.

Brown, G.C., 1992. Control of respiration and ATP synthesis in mammalian mitochondria cells. Biochemical Journal 284, 1-13.

Cardoso, C.M.P., Custódio, J.B.A., Almeida, L.M., Moreno, A.J.M., 2001. Mechanisms of the deleterious effects of tamoxifen on mitochondrial respiration rate and phosphorylation efficiency. Toxicology and Applied Pharmacology 176, 145-152.

Cardoso, C.M.P., Moreno, A.J.M., Almeida, L.M., Custódio, J.B.A., 2002. 4-Hydroxytamoxifen induces slight uncoupling of mitochondrial oxidative phosphorylation system in relation to the deleterious effects of tamoxifen. Toxicology 179, 221-232.

Charlier, C., Chariot, A., Antoine, N., Merville, M., Gielen, J., Castronovo, V., 1995. Tamoxifen and its active metabolite inhibit growth of estrogen receptor-negative MDA-MB-435 cells. Biochemical Pharmacology 49, 351-358.

Coezy, E., Borgna, J.L., Rochefort, H., 1982. Tamoxifen and metabolites in MCF-7 cells: correlation between binding to estrogen receptor and inhibition of cell growth. Cancer Research 42, 317-323.

Couldwell, W.T., Weiss, M.H., Degiorgio, C.M., Weimar, L.P., Hinton, D.R., Ehresmsan, G.R., Conti, P.S., Appuzo, M.L.J., Korblith, P., Detriboler, N., 1993. Clinical and radiographic response in patients with recurrent malignant gliomas treated with high-dose tamoxifen. Neurosurgery 32, 485-490.

Croxtall, J.D., Emmas, C., White, J.O., Choudhary, Q., Flower, R.J., 1994. Tamoxifen inhibits growth of oestrogen receptor-negative A549 cells. Biochemical Pharmacology 47, 197-202.

Daniel, C.P., Gashell, S.J., Nicholson, R.I., 1984. The measurement of tamoxifen and metabolites in the rat and relationship to the response of DMBA-induced mammary tumors. European Journal of Cancer and Clinical Oncology 20, 137-143.
Dietze, E.C., Caldwell, L.E., Grupin, S.L., Mancini, M., Seewaldt, V.L., 2001. Tamoxifen bur not 4-hydroxytamoxifen initiates apoptosis in p53(-) normal human mammary epithelial cells by inducing mitochondrial depolarization. The Journal of Biological Chemistry 276, 5384-5394.

Fattman, C.L., An, B., Sussman, L., Dou, Q.P., 1998. p53-independent dephosphorylation and cleavage of retinoblastoma protein during tamoxifen-induced apoptosis in human breast carcinoma cells. Cancer Letters 130, 103-113.

Gornall, A.G., Bardawill, C.J., David, M.M., 1949. Determination of serum proteins by means of the biuret reaction. The Journal of Biological Chemistry 177, 751-766.

Gupta, R.G., Milatovic, D., Dettbarn, W.-D., 2001. Depletion of energy metabolites following acetylcholinesterase inhibitor-induced status epilepticus:protection by antioxidants. NeuroToxicology 22, 271-282.

Jordan, V.C., Koch, R., Langan, S., McCague, R., 1988. Ligand interaction at the estrogen receptor to program antiestrogen action: a study with non-steroidal compounds in vitro. Endocrinology 122, 1449-1454.

Jordan, V.C., 1990. Long-term adjuvant tamoxifen therapy for breast cancer. Breast Cancer Research Treatment 15, 125-136.

Klingenberg, M., 1970. Metabolite transport in mitochondria: an example for the intracellular membrane function. In: Campebell, P.N., Dickens, F. (Eds.), Essays in Biochemistry. Academic Press, New York, pp. 119-159.

Klingenberg, M., Durand, R., Guérin, B., 1974. Analyses of the reactivity of SH-reagents with the mitochondrial phosphate carrier. European Journal of Biochemistry 42, 135-150.

Klingenberg, M., Giebe, K., Scherer, B., 1975. The binbing of atractylate and carboxyatractylate to mitochondria. European Journal of Biochemistry 52, 351-363.

Laurence, J., Cooke, H., Sikder, S.K., 1990. Effect of tamoxifen on regulation of viral replication and human immunodeficiency virus (HIV) long terminal repeat-directed transcription in cells chronically infected with HIV-1. Blood 75, 696-703.

Lien, E.A., Solheim, E., Ueland, P.M., 1991. Distribution of tamoxifen and its metabolites in rat and human tissues during steady-state treatment. Cancer Research 51, 4837-4844.

Luxo, C., Jurado, A.S., Custódio, J.B.A., Madeira, V.M.C., 1996. Use of Bacillus stearothermophilus as a model to study tamoxifen-membrane interactions. Toxicology in Vitro 10, 463-471.

Madeira, V.M.C., Antunes-Madeira, M.C., Carvalho, A.P., 1974. Activation energies of the ATPase activity of sarcoplasmic reticulum. Biochemical and Biophysical Research Communications 58, 897-904.

Mandlekar, S., Kong, A.N., 2001. Mechanisms of tamoxifen-induced apoptosis. Apoptosis 6, 469-477.

Moreno, A.J.M., Madeira, V.M.C., 1991. Mitochondrial bioenergetics as affected by DDT. Biochimica et Biophysica Acta 1060, 166-174.

Neven, P., Vernaeve, H., 2000. Guidelines for monitoring patients taking tamoxifen treatment. Drug Safety 22, 1-11.

Obrero, M., Yu, D.V., Shapiro, D.J., 2002. Estrogen receptor-dependent and estrogen-independent pathways for tamoxifen and 4hydroxytamoxifen-induced programmed cell death. The Journal of Biological Chemistry 277, 45695-45703.

Osborne, C.K., Wiebe, V.J., McGuire, W.L., Ciocca, D.R., DeGregorio, M.W., 1992. Tamoxifen and the isomers of 4-hydroxytamoxifen in tamoxifen resistant tumors from breast cancer patients. Journal of Clinical Oncology 10, 304-310.

Pederson, P.L., 1999. Mitochondrial events in the life and death of animal cells: a brief overview. Journal of Bioenergetics and Biomembranes 31, 291-304.

Perry, R.R., Kang, Y., Greaves, B., 1995. Effects of tamoxifen on growth and apoptosis of estrogen-dependent and-independent human breast cancer cells. Annals of Surgical Oncology 2, 238245 . 
Radmacher, M.D., Simon, R., 2000. Estimation of tamoxifen's efficiency for preventing the formation and growth of breast tumors. Journal of the National Cancer Institute 92, 48-53.

Roussel, D., Chainier, F., Rouanet, J.-L., Barré, H., 2000. Increase in the adenine nucleotide translocase content of duckling subsarcolemmal mitochondria during cold acclimation. FEBS Letters 477, 141-144.

Sauvez, F., Drouin, D.S., Attia, M., Bertheux, H., Forster, R., 1999. Cutaneously applied 4-hydroxytamoxifen is not carcinogenic in female rats. Carcinogenesis 20, 843-850.

Stocchi, V., Cucchiarini, L., Chiarantini, L., Palma, P., Crescentini, G., 1985. Simultaneous extraction and reverse-phase high-performance chromatographic determination of adenine and pyridine nucleotides in human red blood cells. Analytical Biochemistry 146, $118-124$.

Trope, C., Marth, C., Kaern, J., 2000. Tamoxifen in the treatment of recurrent ovarian carcinoma. European Journal of Cancer 36, 59-61.

Vignais, P.V., 1976. Molecular and physiological aspects of adenine nucleotide transport in mitochondria. Biochimica et Biophysica Acta 456, 1-38.

Wallace, K.B., Starkov, A.A., 2000. Mitochondrial targets of drug toxicity. Annual Review of Pharmacolology and Toxicology 40, 353-388.

Zhou, S., Starkov, A., Froberg, K., Leino, R.L., Wallace, K.B., 2001. Cumulative and irreversible cardiac mitochondrial dysfunction induced by doxorubicin. Cancer Research 61, 771-777. 